\title{
Transitioning the Dominican Republic: regimes, niches and scenarios
}

\author{
Daniël Amrish Lachman \\ Institute for Graduate Studies and Research and Mechanical Engineering Discipline, Anton de Kom University of Suriname; FHR Lim A \\ Po Institute, Paramaribo, Suriname \\ Email address: \\ danny_lachman@yahoo.com \\ To cite this article: \\ Daniël Amrish Lachman. Transitioning the Dominican Republic: Regimes, Niches and Scenarios. American Journal of Energy \\ Engineering. Vol. 2, No. 1, 2014, pp. 37-50. doi: 10.11648/j.ajee.20140201.15
}

\begin{abstract}
Energy security in the Dominican Republic is far from acceptable; black-outs, high tariffs, politicized decisions etc. are common. Furthermore, the future outlook seems worse due to effects of the global economy, climate change, oil prices, further degradation of the existing system, etc. A transition towards sustainable alternatives is therefore mandatory. In this paper a combination of existing concepts and approaches is used to indentify possible roadblocks and windfalls for such a transition in the Dominican Republic. This combination starts with defining the unit of analysis, after which actors in the socio-technical energy system are charted through literature research and interviews. Next, using social network analysis, regimes and niches are identified to depict the unit of analysis in a more useful manner for managing transitions. The step hereafter consists of creating internal and external scenarios based on critical uncertainties to insure transition management efforts against uncertainty. Moving to Transition Management, robustness analysis is then used to evaluate strategies and policies in all combinations of these internal and external scenarios to get to an optimum set of strategies and policies which are used to form a normative scenario. This will be used to get stakeholders behind the transition effort. The results are a clear overview of the energy system, impediments and opportunities regarding transitions, possible futures, and the validity of strategies and policies in different scenarios for the Dominican Republic.
\end{abstract}

Keywords: Energy System Transition Management, Socio-Technical Systems, the Dominican Republic

\section{Introduction}

The world is on an unsustainable path when it concerns the energy usage which forms the basis for almost all activity undertaken by mankind. There are three main reasons for this: the majority of the energy supply is provided by finite fossil fuels; transformation of these fossil fuels into readily usable energy for the consumer generates greenhouse gases that contribute in a significant way to global warming and subsequently to climate change; demand for energy services is growing primarily due to population and economic growth in developing countries.

Hence, the last decades a lot of effort has been put into place in academia, politics, business and other groups to create so-called "sustainable energy systems", meaning energy systems which have a negligible negative impact on the environment on short, middle and long term which would otherwise result in climate change. However, transitioning towards such energy systems has proven to be difficult due to the fact that existing unsustainable energy systems in use are firmly embedded in society in terms of sunk costs en vested interests; their socio-technical nature a term that encompasses the technological, social, political, regulatory, and cultural aspects of electricity supply and use (Sovacool 2009) - has influenced and formed engineering practices, academia, legislation, institutes, behavior, spatial planning, among other things, all of which need to change (some more than others) if a new energy system is taking center stage. Another reason is also found in the fact that such a transition on a global scale will cost enormous sums of money and consume years (if not decades) and thus prove to be difficult, in particular for developing countries. Therefore, a lot of research regarding "energy system transition" has emerged and intensified in the last decades, spawning several academic courses, journals and articles, and various approaches to understand and manage transitions.

Developing countries in particular are in need of energy system transitions (Lachman 2013). This paper scrutinizes roadblocks and windfalls regarding energy system 
transitions in the Dominican Republic and examines the borders that make up the realm of energy system transition management. To do this, a methodology consisting of existing approaches has been used which addresses important transition aspects such as regimes, niches, landscape factors, uncertainty, etc., all of which will be explained in this paper.

This paper is structured as follows: in the next section, the methodology is explained in detail. The section thereafter reflects on and discusses this methodology. The fourth section applied this methodology in the case of the Dominican Republic. The last section concludes this paper and provides a number of recommendations, and is followed by an alphabetical list of references.

\section{Methodology}

The methodology is aimed at understanding the construction and dynamics of socio-technical systems, and how to manage these in such a way that leverage points are identified and utilized to ignite and accelerate the transition of these systems towards desirable alternatives. Its steps are: conducting interviews and performing a literature study in order to be able to perform a social network analysis (to obtain a clear picture of the unit of analysis, viz. the energy sector, and its construction), and to identify landscape factors (influences originating from outside the energy system) which are categorized into predetermined elements and critical uncertainties (the first are those factors that have expected developments, while the latter comprise factors whose developments are unpredictable). The next step is re-arranging the charted social network in such a manner that sets of regimes and niches become apparent. Next, scenarios are constructed (including a normative scenario) using the earlier mentioned landscape factors and other indicators. The final step consists of using robustness analysis and the normative scenario to guide transition management. The steps are detailed in the following subsections.

These steps are intertwined: information obtained through interviews and desk research is used in social network analysis and to identify landscape factors. These results are used to depict the unit of analysis in a more useful manner (more on this in section 2.4) for managing transitions and the latter is used to create scenarios for this unit of analysis (detailed in section 2.5). These scenarios are used to insure transition management efforts against uncertainty both within the unit of analysis as well as in external (landscape) influencing factors. Validating strategies, policies and actions against each scenario and iteratively tracking towards which scenario the present is heading is embedded in transition management (see section 2.6). Thus in this paper, the social network analysis and scenario creation form the foundation which transition management builds upon.

\subsection{Define the Unit of Analysis}

It is important to start with carefully defining the unit of analysis. Since this paper focuses on the transition from one energy system to another, the unit of analysis will be a socio-technical energy system by definition, but the questions remains as to how large the scope will be, in other words, whether the energy system of a region, country, group of countries, etc., will be placed under scrutiny. Properly defining the unit of analysis will prevent the omission of important actors in the socio-technical energy system, and make a proper distinction between internal and external (regarding the energy system) influencing aspects (which will be called "landscape factors" from subsection 2.2 on). Partly due to these reasons, a proper definition will also influence which questions need to be asked in the interview process (which is discussed in the next subsection). It should be noted as a cautionary warning that a larger unit of analysis will automatically result in a longer and more difficult process (because of more actors, variables, data, etc.).

\subsection{Conduct Interviews}

After the unit of analysis is defined, interviews need to be conducted. To do this in a proper and efficient manner, the following actions need to be undertaken:

- actors that are part of the socio-technical energy system need to be identified, for instance by researching websites, newspapers, magazines, etc.;

- a questionnaire needs to be conceived which is flexible in structure (i.e. the interviewer is allowed to ask additional questions, alter the sequence of questions, apply small changes to the questions, etc.), but also grounded in the local context (Bulmer and Warwick 1993). The questionnaire needs to address the following topics:

- the strength of ties between the different actors within the energy system

- landscape factors (named "driving forces" in scenario planning literature), which refer to events and trends occurring outside the confines of the energy system but which do have an impact on the system (Geels 2002, Shove 2012). Furthermore, questions need to unravel whether these landscape factors belong to the category of predetermined elements (forces of change whose development and impact over time can more or less be estimated), or critical uncertainties (unpredictable driving forces that will have an important and sudden impact on a particular area of interest). These driving forces can be divided into social, technological, economic, environmental and political factors that form the structure in the landscape (the contextual environment) from which trends and events emerge (van der Heijden 2005)

o driving forces within the energy system (also categorized in predetermined elements and critical uncertainties) 
- leading indicators which are used to anticipate towards which scenario the present socio-technical energy system is heading (Conway 2004)

The interview process will be characterized by nonprobabilistic sampling since the interviewer is directly targeting actors in the socio-technical energy network, rather than using a sampling frame from which actors will be randomly picked. Furthermore, to enhance the search for relevant actors, sampling will also be characterized by the snowball effect, which refers to gaining access through the initial respondents to other relevant observational units (Bryman 2004).

It is possible that the interviewer is unable to identify all actors within the energy system. However, if the research to determine the actors has been done properly, it can be assumed that those unidentified actors play a marginal role within the energy system - and even in the niches of that system (which will be discussed in more detail in the next subsection) - and thus their impact can be neglected.

\subsection{Social Network Analysis}

Utilizing the information obtained through research and interviews, the strength of the ties between different actors in the socio-technical energy system is made visual. The definition of tie strength is of the utmost importance. It can be defined in a quantitative sense (e.g. by using the frequency of recent contact as the definition of tie strength) or in a qualitative manner, i.e. through evaluation of qualitative information obtained through interviews and other research (Granovetter 1983). Tie strength is then rated according to a numerical scale with values that associate with a range from "very weak" to "very strong". This information can be presented in a matrix with a size $Y$ $\mathrm{x} Y$, where $\mathrm{Y}$ stands for the amount of actors, and with the tie-values in respective cells (Hanneman and Riddle 2005).

The energy network, consisting of actors and their ties can also be made visual using Graph Theory where actors are represented by nodes that are connected by means of weighted edges, which in turn represent ties (Hanneman and Riddle 2005, Izquierdo and Hanneman 2006), see figure 1 .

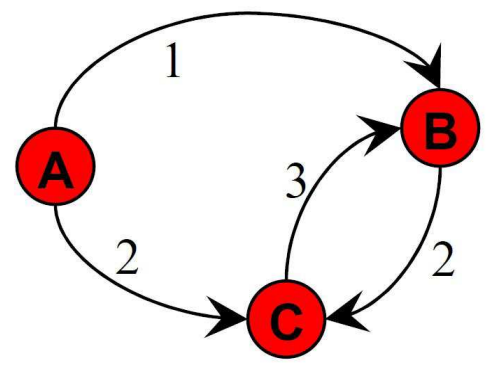

Figure 1. Actors connected by means of weighted edges (Izquierdo and Hanneman 2006)

Making an energy network visual as in figure 1 can be done manually or using a numerical program, such as UCINET with NetDraw.

\subsection{Identify the Multi-Level Structure}

The next step consists of rearranging the visualized energy network in such a manner that different groups of actors are made apparent and place the network in a wider context. This step dives deeper into social network analysis, but particularly borrows from the Multi-Level-Perspective (MLP) which has its origins in Twente school's quasievolutionary theory (Geels 2010a).

The Multi-Level Perspective builds on evolutionary thinking (in the sense that it assumes that variation, selection and retention play an important role in the development of systems) and interpretivism that conceptualizes a pattern of long-term change. It consists of a macro, meso and micro level, respectively landscape factors, regimes and niches (Rip and Kemp 1998, Geels 2002):

- Landscape level: the whole set of exogenous impacts on the energy system (like autonomous trends and global events). The energy system itself has little to no influence on the landscape level, but landscape factors can have a significant impact, that can even result in systemic changes (i.e. the rearrangement of the locations of actors within the system);

- Regime level: this level consists of a patchwork of regimes, each consisting of 1 or more dominant actors. The regime concept refers to "the rule-set or grammar embedded in a complex of engineering practices, production process technologies, product characteristics, skills and procedures, ways of handling relevant artifacts and persons, ways of defining problems, etc., which is engrained in institutions and infrastructures". The regime consists of three interlinked elements: (1) a network of actors and social groups, which develops over time; (2) the set of formal and informal rules that guide the activities of actors who reproduce and maintain the elements of the socio-technical system and (3) the material and technical elements (Geels 2004). Regimes co-evolve with each other but also with the environment (landscape).

A change in regimes implies a change in the system in which it functions. Regimes resist systemic change and thus also niches (which are described below). As long as regimes themselves are stable, and the landscape is not unfavorable, regimes create a strong alignment between different elements of the system in which it operates (thus increasing its momentum), thereby making the entire system path dependent / locked in (Raven and Verbong 2007). Even change within regimes follows a dependent path and tends to be incremental;

- Niche level: niches are the spaces where innovative activity takes place and where time-limited protection is offered against dominant selection rules. Niches also tend to be very flexible and adaptive. Thus, they differ from regimes and aim to replace the incumbent regime (which can happen under the right set of 
conditions), thereby creating new development trajectories. Initially, only technological and market niches were identified; however, Geels (2007) discovered that niches have general relevance.

Figure 2 provides a representation of the Multi-Level Perspective.

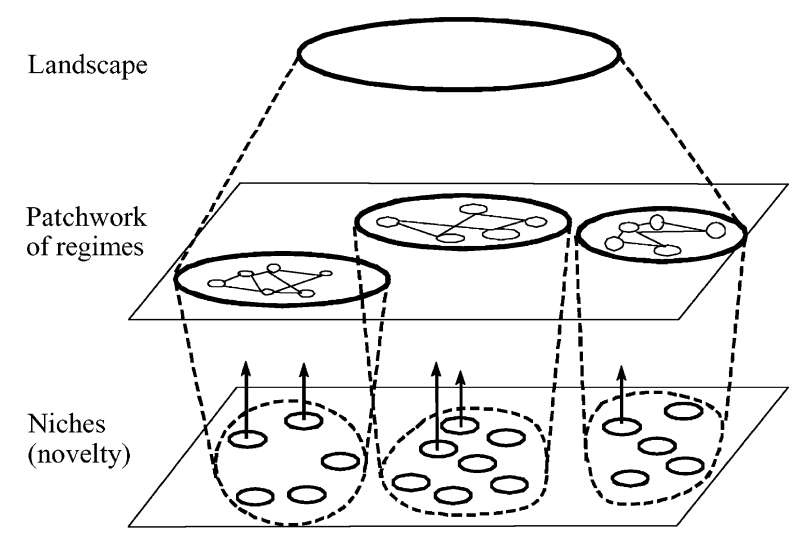

Figure 2. Representation of the multi-level perspective (Geels 2002)

According to the MLP, transitions occur as a result of dynamics at the different levels which reinforce each other creating a "window of opportunity": landscape factors destabilize regimes (actors diverge and start to disagree) while niches, developed in protective spaces, gather momentum to take center stage within the system (Geels 2006, Grin et. al. 2010).

At this point in the methodology, actors need to be grouped in order to visualize regimes and niches. Regimes and niches make up the energy system, and the level remaining is the context (landscape) within which this system exists. This macro level can be described by the external driving forces (consisting both of predetermined elements and critical uncertainties) that have been identified during the research in the first two steps.

With the information now on hand, the multi-level structure of the energy network under consideration can be conceived. It provides a snapshot of the socio-technical system which - due to its rearrangement highlighting regimes and niches placed within the landscape - is an effective manner to present a complex network.

\subsection{Create Scenarios}

Socio-technical energy systems are complex systems situated in and influenced by a complex landscape. Both the energy system and the landscape have a degree of uncertainty which makes it difficult to manage transitions to sustainable energy systems. This aspect of uncertainty comprises (Schwartz and Ogilvy 1998):

- risks: based on historical data, a probability can be assigned that a certain event will happen;

- structural uncertainty: an event is unique in such a way that (judgmental) probabilities of the event happening are unknown;

- unimaginable events.
It is therefore imperative that a tool is available which enables to deal with the aspect of uncertainty in order to be able to strategize and manage the transition. This is where Scenario Planning comes in the picture; it is a management thinking tool that acknowledges the existence of uncertainty in the organization and its environment by developing a set of scenarios (internally consistent and plausible, but structurally different narratives), which outline the range of possible futures (van der Heijden 2005). It enables to see opportunities and threats in advance and helps in generating more robust strategies, policies and plans (Star and Randall 2007). Scenario Planning has its origins in the Second World War and has proven its worth ever since, as evidenced by the growing number organizations (private companies, governments, and Non-Governmental Organizations etc.) using the methodology (Ogilvy and Smith 2004).

The scenarios are not predictions, but rather hypotheses in the form of rather provocative, structurally different, but internally consistent and plausible narratives, built upon combinations of uncertain, high-impact Driving Forces, about how the future of issues relevant to an organization or individual might unfold (Scearce et. al. 2004). A set of scenarios (each treated with equal weight) outlines the range of possible futures. The scenarios are used to:

1. Set the strategic direction and prepare a rough timetable of events;

2. Be more perceptive of the environment when trying to identify towards which scenario the present is evolving, and anticipate new insights and innovations;

3. Accelerate collaborative learning by providing insight in the environment during the scenario building process;

4. Test existing strategies by challenging assumptions upon which they are built;

5. Rehearse the actions that need to be taken in different environments;

6. Describe goals that need to be achieved (so-called normative scenarios).

There are various approaches to Scenario Planning which can be found in van der Heijden (2005) and Nekkers (2007). In this paper use will be made of the deductive method, which combines extremes of critical uncertainties in a matrix to form the structure upon which scenarios are built (see figure 3).



Figure 3. A scenario-matrix (also known as the scenario logic) 
The deductive scenario-matrix method has the following advantages over other methods (Scearce et. al. 2004, van der Heijden 2005, Nekkers 2007):

1. due to its nature the method is more likely to produce surprises that challenge existing assumptions;

2. the method is more likely to develop scenarios that cover a wide range of possible futures;

3. the deductive approach is the most analytical Scenario Planning method.

In this phase of the methodology, internal and external scenarios are created to cope with uncertainties which exist in the socio-technical energy system itself and its landscape in order to manage transitions. Regarding internal scenarios, information obtained in the first two steps (desk research and interviews) is scrutinized to identify driving forces of change within the energy system. Similar forces are clustered into larger (underlying) driving forces, which are split into predetermined elements and critical uncertainties. The extremes of the two most uncertain and highest impact driving forces are then plotted on an $\mathrm{X}-\mathrm{Y}$ axis to create the so-called scenario logic, after which narratives are conceived for each scenario that make up each respective quadrant in the matrix (Scearce et. al. 2004, van der Heijden 2005, Nekkers 2007).

The narratives should link the present state (as described in section 2.4) with the future description, and include the predetermined Driving Forces in each scenario. The scenarios are depicted as short narratives, because these can quickly capture complex matters, embed qualitative information that can not be depicted by means of graphs and tables, make unexpected scenarios believable, and leave a lasting message (van der Heijden 2005). The scenarios need to be internally consistent, structurally different from each other, challenging (they need to display a new and unique perspective), relevant and plausible.

A similar exercise is done for the creation of external scenarios, but instead of using driving forces that exist in the system, driving forces from the landscape level are used (discussed in section 2.4). It is important to note that the researcher pays particular attention during the desk research and interviews to specific local characteristics (on the level of the energy system, region, country, etc.) which can be driving forces that are most relevant for the creation of internal and external scenarios (Lachman 2011).

The researcher has thus created 4 internal and 4 external scenarios which enable to anticipate sudden changes within the socio-technical energy system and within the landscape in which the system functions. Examples of scenarios (which are actually a combination of both internal and external developments) can be found in Lachman (2011).

\subsection{Formulate Strategy and Create Management System}

In this final step, the focus is on the "Transition Management" (TM) concept, which, like the Multi-LevelPerspective, has its origins in Twente School's quasievolutionary theory and is part of what is known as "transition studies". Transition management is a reflexive and participative governance concept that attempts to manage transformative change (i.e. influence the speed and direction of change) towards sustainable development by combining long-term thinking with short term action (thus complementing conventional policy) through a process of searching, experimenting and learning (Loorbach and Rotmans 2006). It is a concept that has gained significant traction in the last decade. Key aspects on TM are:

- Experimenting and learning to guide variation and selection (learning-by-doing and doing-by-learning) while not chasing "silver bullets" (thus keeping all options in consideration and the playing field open). This characteristic of continuous learning places TM in the so-called "Processual Paradigm" school of thought (van der Heijden 2005);

- Obtaining stakeholder (from multiple domains and levels) input through inclusion and involvement;

- Complementing conventional policy (which has a short-term focus) with long-term thinking with the aim of sustainable development;

- Continuous reflection (monitoring, evaluating, improving) on all levels;

- Bringing system innovation alongside system improvement.

Transition management is executed on a strategic, tactical and operational level; these three levels follow a cyclical path consisting of problem structuring and envisioning (strategic level), agenda building and networking (tactical level), experimenting and diffusing (operational level), and executes continuous monitoring, evaluating and adjusting on all levels (Loorbach et. al. 2008).

As part of Transition Management, the Robustness Analysis method is used to determine the best strategy (or set of strategies) and policies to drive the energy system transition. Each internal scenario is placed against each external scenario (both of which were created earlier in the process), resulting in 16 internal-external scenario combinations. Using a matrix (table 1), various strategies and policies can be evaluated in case of each scenario combination. This is done, for instance, by assigning a plus-, zero- or minus-sign, respectively indicating a positive, neutral or negative effect on the energy system transition. This comparison of strategies and policies under each scenario is known as Robustness Analysis (Taylor 1999). An example of a Robustness Analysis exercise can be found in Lachman (2011).

Table 1. An example of a Robustness Analysis exercise




On a strategic level, a normative scenario can be conceived once the most suitable set of strategies and policies are identified through the Robustness Analysis exercise. This scenario describes how these strategies and policies are used to arrive at a plausible and realistic (taking into account present conditions and internal and external driving forces) future state (Nekkers 2007). The normative scenario is used to align and engage multiple stakeholders in a so-called transition arena where vision, goals, roadmaps and milestones are defined based on this normative scenario and the confrontation of different perceptions of and possible directions for the energy system transition (Loorbach and Rotmans 2006, Loorbach 2010).

The results from this strategic level are the framework for the tactical level, where the focus is on conceiving a transition agenda towards the desired goal with the consent of the actors in the transition arena (aligning the actors can be achieved by using the normative scenario and the robustness analysis). Next, at the operational level the execution of the agenda takes place, with a special focus on

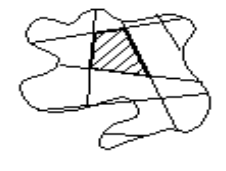

1. Define unit of amalysis
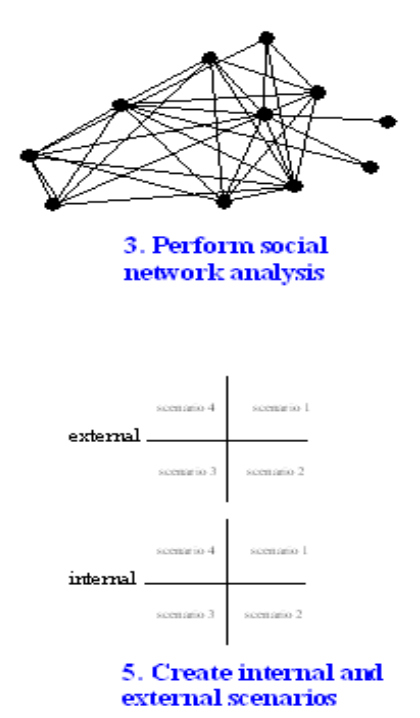

Figure 4. Visual representation of the methodology experiments, rather than "silver bullets", to stimulate learning and thereby guide variation and selection and thus ensure continuous improvement (Loorbach 2010).

To ensure that activities undertaken on all three level remain relevant under changing conditions, adjustments (e.g. of roadmaps, agenda, actions) are done by endlessly tracking leading indicators (this also fosters continuous learning). These indicators point towards which scenario the present is heading, and can be obtained from the earlier conducted interviews and desk research (Lachman 2011). The work done by Hekkert et. al. (2007) also provides some examples of leading indicators used in the Innovation Systems literature. On a larger timescale (e.g. every 5 years), continuous learning, adjustment and improvement is also fed by updating the internal and external scenarios (van der Heijden 2005).

\subsection{Visual Representation of the Methodology}

The steps in the described methodology are depicted below in a simplified manner.


6. Formulate strategy and manage the transition

\section{Reflections on the Methodology}

The described methodology is both qualitative and quantitative in nature, in the sense that it gathers qualitative data (obtained through interviews and desk research) and processes this data by assigning various categories and weights, which subsequently are used to perform several numerical exercises, e.g. in the case of social network analysis. After completing the social network analysis, qualitative (and to a lesser extent quantitative) endeavors are performed when creating various types of scenarios which are used in the quantitative robustness analysis method to conceive the normative scenario (which is again a qualitative exercise). It is therefore clearly evident that it is difficult to place the approach strictly under one of these orientations; rather, the methodology shifts from 
qualitative to quantitative methods, and vice versa (Bryman 2004).

Similar to its research orientation, the methodology is both inductive and deductive in nature; the path to conceive an overview of the socio-technical energy system and the scenarios is clearly inductive, whereas formulating strategies and managing the transition by means of the transition arena, experiments, etc., all derived from the earlier mentioned energy system and scenarios is deductive (Minto 1996). Since the energy system overview, the scenarios, and early indicators need to be updated over time as changes in the landscape become apparent, the subsequent actions on a strategic, tactical and operational level need to be adjusted likewise (van der Heijden 2005). Therefore, this methodology needs to be repeated with a specific frequency in order to adjust transition management strategies and tactics, which implies that this cycle from induction to deduction is required to be repeated during the management of the transition.

From an epistemological perspective, the methodology has traces of phenomenology due to the fact that it is important during the construction of the socio-technical energy network (and its restructuring along the lines of the Multi-Level Perspective) and the scenarios to understand how various social groups, in particular regimes and niches, view the socio-technical energy system and the landscape within which this system operates. Subsequently, the methodology is also interpretivist in nature since it attempts to grasp the subjective meaning behind social action (Bryman 2004) which is formed because of the earlier mentioned perception of reality. This is evident when scenarios (narratives that discuss these meanings behind social actions to render the scenario plausible) are constructed and when shifts in the direction of the unfolding present is becoming apparent through the use of early indicators (which can convey drivers for social action).

When scrutinizing the approach from an ontological point of view, it is important to note the fact that the approach builds upon the notion that the energy system is being regarded as a socio-technical entity. This means that social actors and (technical) artifacts influence each other to such an extent that they shape each others developmental trajectory. Therefore, this clearly indicates that the methodology has a strong constructionist flavor.

It also noteworthy to mention that the methodology is also strongly characterized by the fact that it is an exploratory process at heart; the reasons for this lie in the fact that the approach centers on the observation of phenomena from which the researcher can identify concepts such as driving forces, early indicators, regimes and niches (Bulmer and Warwick 1993). These are in turn are used to create networks and scenarios (which in effect is the inductive portion as described earlier).

The underlying research design is of a mixed nature: there are elements of both a case-study and a longitudinal analysis. The case-study approach is evidenced by the fact that in-depth research (ranging from literature study, to interviews, robustness analysis, social network analysis, and so on) is done on a particular unit of analysis, which has been carefully chosen with its boundaries properly defined. The longitudinal element of the design is apparent where scenarios are created, since these scenarios formulate of plausible path between the current condition and a particular future state, thereby connecting two points in time.

The described methodology has some advantages; it bridges the gap between understanding the socio-technical energy network and landscape factors (driving forces) on one hand, and concrete activities on a strategic, tactical and operational level to advance a desired transition on the other hand. Secondly, the approach is quite analytical in nature due to its quantitative efforts to create the sociotechnical energy network - which also eases comparisons between different energy networks -, lay out its possible (and plausible) developments over time through the use of scenarios, conceive a normative scenario based on the results from a robustness analysis, and managing the transition strategy by keeping track of so-called early indicators, most of which are quantitative in nature. Furthermore, the methodology exercises a form of transition management which is highly flexible and adaptive to (suddenly) changing circumstances through its use of scenarios and the robustness analysis, which is important since the global landscape is increasingly changing, while becoming more complex and unpredictable. Another advantage lies in the fact that the visualizations of regimes and niches in the socio-technical energy system, the various scenarios, an overview (provided by the robustness analysis) of the merits and perils of various strategies, policies and actions in different combinations of internal and external scenarios, can be used in the transition process as powerful communication tools regarding a rather abstract and complex matter.

These benefits notwithstanding, the methodology has some drawbacks and pitfalls; since it consists of several approaches, the drawbacks to each will be discussed (Lachman 2013):

1. The methodology can prove to be quite resource consuming (in particular the stage concerning desk research and interviews) depending of the unit of analysis chosen;

2. With regard to the purposive, non-probabilistic, sampling using unstructured, flexible and even adaptive techniques, the same results will be difficult to obtain in an exactly repeated manner. Therefore, the methodology has a low replicability. However, the validity is regarded to be high, since the method is likely to deliver results relevant to the research questions (Bryman 2004);

3. The interview process can be hampered due to nonresponse, interviewer variance, and the difficulty of the interviewee to grasp abstract notions such as 
landscape, scenarios, driving factors, regimes, and so on (Billiet et. al. 1990);

4. Another pitfall is that the scenarios are often not viewed as the outline of possible futures but as predictions of what may come, thereby nullifying the adaptive ability of transition management (Nekkers 2007);

5. the MLP uses metaphors and imprecise concepts, with the danger of creating ambiguity and being able to categorize phenomena too easily since the concepts have vague boundaries (Smith et. al. 2010);

6. Another drawback of the MLP is its complexity; it might seem straightforward, but attention is required to dynamics between levels and between actors of the same level, resulting in a myriad of events, actors and relations that need to be taken into account, especially when applying the MLP at relatively large transitions. This complicates the conception of computer models (Geels 2010a);

7. TM conveys the idea that a transition can be accomplished through the execution of proper management; transitioning is a managerial task. However, with this assumption, the scope of the transition task is simplified by neglecting the fact that influences exist - both inside and outside the transition management realm -, such as belief systems, political interests, and culture, which obstruct or even prohibit managing transitions according to best management practices and rules (Shove and Walker 2007, 2008).

\section{Transition Pathways for the Dominican Republic}

In this section, the aforementioned combination of concepts and approaches will be used in the case of the Dominican Republic.

\subsection{Unit of Analysis}

The unit of analysis will be the total energy sector, consisting of electricity generation, transmission and distribution and (fuels for) the transportation sector. The sector is characterized by a total installed electricity generation capacity of around $3600 \mathrm{MW}$ and consumes about 10 billion $\mathrm{kWh}$. Of its installed capacity, around $84 \%$ is covered by thermal generation (of which $20 \%$ is delivered by one company) and the remaining part by hydro power (which expanded in 2011 with $550 \mathrm{MW}$ ) and there are plans for another $600 \mathrm{MW}$ of thermal generation. All of the fossil fuels are imported and in 2010 totaled $7 \%$ of GDP or \$ 3.5 billion. Other energy generation technologies are barely existent (e.g. $33 \mathrm{MW}$ of wind power and some bio-fuel initiatives). The sector has an open market where vertical integration is allowed, though hydro power and transmission are run by the state. There are three public and one private distribution companies (Burgos, 2008).

The Dominican Republic has negligible fossil fuel reserves, and only uses hydro power as its renewable source, though there are other alternative energies in abundance: solar power potential is around 150,000 $\mathrm{GWh} /$ year and approximately $4,400 \mathrm{~km} 2$ is useful for wind energy generation, equaling 30,000 MW (Elliot et. al. 2001). There are a few micro-scale utilizations of these technologies, though there are plans to expand on that portfolio, but nothing concrete has been set in stone. There have also been talks about a Haiti-Dominican Republic interconnection, though many have deemed it uneconomical (Nexant, 2010).

Total electrification amounts to $95.7 \%$, whereas rural electrification is close to $90 \%$ and unserved totals $15 \%$. Technical and non-technical losses are estimated to be between $34-40 \%$, of which illegal connections take up about $18 \%$. On top of these problems, there are frequent black outs (lasting up to 20 hours), despite the fact that the electricity tariffs are among the highest in the region and electricity subsidies exceed $\$ 1$ billion, while energy consumption is increasing annually with $10 \%$ (Burgos 2008). It is estimated that there is an energy supply deficit of 2,000-2,300 MW.

The country has an electricity sector and renewable energy law. The National Energy Commission is the policy agency, one of its main responsibilities being the elaboration of the National Energy Plan. The Electricity Superintendence is the regulatory agency, while the Coordination Agency was created to coordinate dispatch of electricity. The Dominican Corporation of State Electricity Companies is a holding company that brings together all government-owned generation, transmission and distribution companies and associated government programs in the country (OAS 2007). The debt owned by the state's agencies to the generators is quite substantial because of lucrative contracts. Plans to renegotiate these contracts are retaliated by the generators by taking electric capacity offline, thus creating black outs, which in turn causes public outrage.

\subsection{Social Network Analysis and Multi-Level Perspective}

Data has been obtained from literature, news articles and interviews. The personal interviews taken from people (knowledgeable about aspects regarding the Dominican energy sector) are able to give deeper insight into informal, largely unknown, subtle or increasingly important becoming forces specific to the Dominican context that shape its socio-technical energy system.

A little over 250 articles, 15 reports, 15 books and 4 film documentaries were reviewed. The topics spanned a wide spectrum and included rural electrification, alternative and conventional energy, climate change, geopolitics, the future of transport, social impact of energy and energy efficiency. 
A total of 15 persons, from the public, and the private (energy) sector, were interviewed. The amount of interviews was sufficient because during the last couple of interviews no new information, i.e. the saturation point (Strauss and Corbin 1998), was obtained. Questions were asked about actors and their ties, landscape factors (both predetermined elements and critical uncertainties), impediments to transition etc. Using the obtained information, table 2 is conceived which depicts the actors in the Dominican energy system and the strength of their ties (A being the lowest, D being the highest) which is visualized in figure 5 .

It can be seen that the generators operating the thermal and hydro power plants take a prominent place within the regime level. This is due to the fact that the government has stakes in their operation and the fact that they are often vertically integrated across the supply chain.

Table 2. Actors and their ties in the energy sector of the Dominican Republic
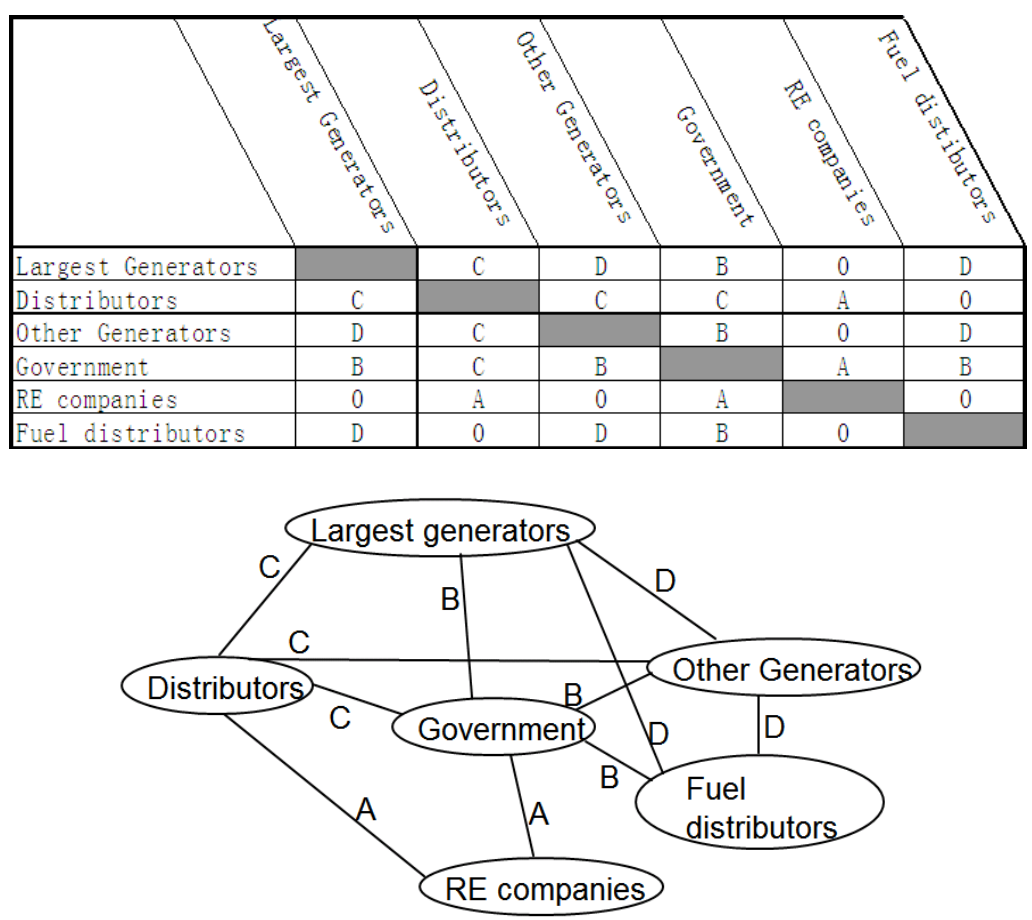

Figure 5. Actors and their strengths in the energy sector of the Dominican Republic

The information in this figure is further rearranged (based on tie strength) into the Multi-Level Perspective format, see figure 6 . In this figure concepts, ideas, approaches, etc. that can play an important role in energy systems transitions have also been included in this figure sorted in the niche and regime category.

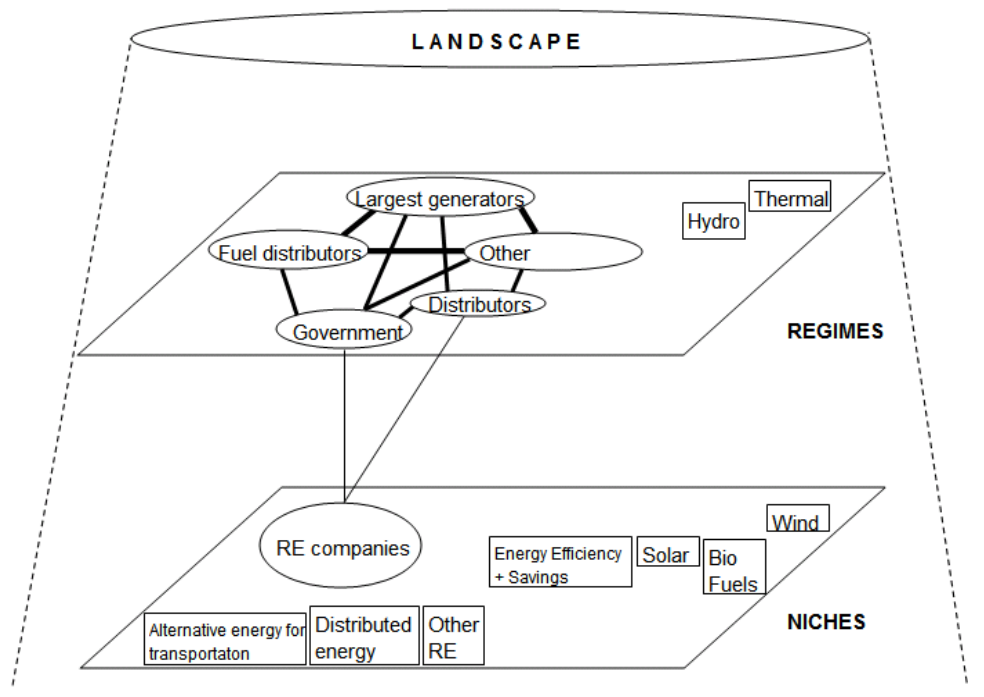

Figure 6. The Multi-Level Perspective applied on the energy sector of the Dominican Republic 
As mentioned earlier, the vertical integration of many of the power companies gives these companies (indirect and direct) control of the deployment of renewable and alternative energy technologies, distributed energy systems etc., and since they benefit from the current situation, they have insufficient incentives to speed up deployment. The lack of deployment is also evidenced that mainly thermal (and to a lesser extent hydro) power is considered in energy plans, accompanied by a couple of wind and bio-fuel projects.

\subsection{Scenario Planning and Robustness Analysis}

From the earlier mentioned desk research and personal interviews, several critical uncertainties have been indentified regarding the future the energy sector in the Dominican Republic is heading to. These critical uncertainties are categorized in internal uncertainties (i.e. internal to the energy sector) and external uncertainties (which belong to the landscape-realm in the Multi-Level Perspective, see figure 6):

Internal Critical Uncertainties

1. The quality of the government regarding (energy) policy making (implementation of existing laws, depoliticizing decisions, ability to deploy unpopular measures);

2. Willingness of the public to accept higher tariffs to improve energy security

3. Willingness of Independent Power Producers (IPPs) to revise existing Power Purchase Agreements (PPAs) which are highly favorable to them;

4. Energy consumption behavior and adoption of energy efficiency and savings guidelines;

5. Perception of new renewable energy projects by affected ethnic / tribal groups;

External Critical Uncertainties

6. Transfer of new energy technologies to the Dominican Republic

7. Climate change the effects thereof on Dominican Republic's energy system and renewable energy potential;
8. Natural disasters and the effects thereof on Dominican Republic's energy system and renewable energy potential;

9. Sudden events, such as the attacks on 11 September 2001, which severely impact the majority of the Dominican economy

10. Oil price behavior;

11. (International) technological breakthroughs and their deployment.

In figure 7 these critical uncertainties are plot according to their level of uncertainty and impact on the energy sector (the numbers refer to the order of these critical uncertainties mentioned above). However, "the quality of the government regarding (energy) policy making" will not be chosen for use in the scenario logic, due to the fact that the ultimate goal of the scenarios will be to formulate resilient and robust strategies, and subsequent policies and actions will mostly fall under the responsibility of the government. Using government quality in the scenario logic will therefore result in normative scenarios, which will describe future governmental action which the government will try to achieve or steer away from (Lachman 2011). The most critical ones (thus those in the upper right corner of the graph) will be used to create internal (public accepting unpopular measures towards energy security and IPPs willing to change PPAs) and external (climate change and impacts on the domestic economy) scenarios, see figure 8 .



Figure 7. Ranking of the internal (blue) and external (green) critical uncertainties



Energy scenarios for the Dominican

Republic based on internal critical uncertainties 
Various strategies, policies and concrete actions regarding the energy sector can now be validated against each combination of internal and external scenarios using the information from the desk research and interviews. In particular, energy system transition strategies, policies and actions (which take strong account of the actors, tie- strengths and the multi-level depiction of the Dominican energy sector) can now be tested in different scenarios and thus can transition management insure itself against future uncertainty regarding the energy sector. The robustness analysis is depicted in table 3 .

Table 3. Robustness Analysis using created internal and external scenarios

\begin{tabular}{|c|c|c|c|c|c|c|c|c|c|c|c|c|c|c|c|c|c|}
\hline \multirow{3}{*}{$\begin{array}{l}\text { Strategies, } \\
\text { actions }\end{array}$} & \multicolumn{17}{|l|}{ Scenario Combination } \\
\hline & \multirow{2}{*}{$\begin{array}{l}\text { Internal Scenarios: } \\
\text { External Scenarios: }\end{array}$} & \multicolumn{4}{|l|}{ A } & \multicolumn{4}{|l|}{ B } & \multicolumn{4}{|l|}{$\mathrm{C}$} & \multicolumn{4}{|l|}{$\mathrm{D}$} \\
\hline & & I & II & III & IV & I & II & III & IV & I & II & III & IV & I & II & III & IV \\
\hline \multicolumn{2}{|c|}{ Expand electricity production through primarily thermal power } & - & + & + & - & - & - & - & - & - & - & - & - & - & + & + & - \\
\hline \multicolumn{2}{|c|}{ Expand use of bio fuels for transportation sector } & - & 0 & 0 & - & - & 0 & 0 & - & - & 0 & 0 & - & - & 0 & 0 & - \\
\hline \multicolumn{2}{|c|}{ Electrify the transportation sector } & + & + & + & + & - & - & 0 & - & - & - & 0 & - & + & + & + & + \\
\hline \multicolumn{2}{|c|}{ Venture into hydrogen fueled vehicles } & - & - & 0 & 0 & - & - & 0 & 0 & - & - & 0 & 0 & - & - & 0 & 0 \\
\hline \multicolumn{2}{|c|}{ Provide incentives for less vehicle use (e.g. carpooling etc.) } & + & + & + & + & + & + & + & + & + & + & 0 & 0 & + & + & 0 & 0 \\
\hline \multicolumn{2}{|c|}{ Provide incentives for fuel-efficient vehicles } & + & + & + & + & + & + & + & + & 0 & 0 & 0 & 0 & 0 & 0 & 0 & 0 \\
\hline \multicolumn{2}{|c|}{ Promote electricity efficiency and energy savings } & + & + & + & + & + & + & + & + & + & + & 0 & 0 & + & + & 0 & 0 \\
\hline \multicolumn{2}{|c|}{$\begin{array}{l}\text { Execute construction of Haiti-Dominican Republic } \\
\text { Interconnection }\end{array}$} & + & 0 & 0 & + & + & 0 & 0 & + & + & 0 & 0 & + & + & 0 & 0 & + \\
\hline \multicolumn{2}{|l|}{ Decentralize energy supply } & + & + & + & + & + & + & + & + & + & + & + & + & + & + & + & + \\
\hline \multicolumn{2}{|l|}{$\begin{array}{l}\text { Create diversified energy } \\
\text { production portfolio }\end{array}$} & + & + & + & + & + & + & + & + & + & + & + & + & + & + & + & + \\
\hline \multicolumn{2}{|c|}{$\begin{array}{l}\text { Rapid deployment of renewable energy technologies apart from } \\
\text { hydro, wind and PV }\end{array}$} & + & + & + & + & + & + & + & + & + & + & + & + & + & + & + & + \\
\hline \multicolumn{2}{|c|}{$\begin{array}{l}\text { Deploy a firm performance-based rewarding scheme for } \mathrm{t} \\
\text { governmental bodies in the energy sector }\end{array}$} & + & + & + & + & + & + & + & + & + & + & + & + & + & + & + & + \\
\hline \multicolumn{2}{|c|}{$\begin{array}{l}\text { Upgrade existing outdated transmission and distribution } \\
\text { network }\end{array}$} & - & + & + & - & - & + & + & - & - & + & + & - & - & + & + & - \\
\hline \multicolumn{2}{|c|}{ Build new transmission and distribution network } & - & - & + & + & - & - & + & + & - & - & + & + & - & - & + & + \\
\hline \multicolumn{2}{|c|}{$\begin{array}{l}\text { Mandate inclusion of renewable energy technologies in } \\
\text { portfolio of IPPs }\end{array}$} & + & + & + & + & + & + & + & + & + & + & + & + & + & + & + & + \\
\hline \multicolumn{2}{|c|}{$\begin{array}{l}\text { Gradually stop cross-subsidizing sectors (clearly communicated } \\
\text { to stakeholders) while investing the recovered funds in energy } \\
\text { saving and efficiency technologies which will lower losses and } \\
\text { thus can potentially lower tariffs }\end{array}$} & + & + & + & + & + & + & + & + & + & + & + & + & + & + & + & + \\
\hline \multicolumn{2}{|c|}{$\begin{array}{l}\text { Immediately stop cross-subsidizing sectors (clearly } \\
\text { communicated to stakeholders) while investing the recovered } \\
\text { funds in energy saving and efficiency technologies which will } \\
\text { lower losses and thus can potentially lower tariffs }\end{array}$} & - & - & - & - & - & - & - & - & + & + & + & + & + & + & + & + \\
\hline \multicolumn{2}{|c|}{$\begin{array}{l}\text { Unite all governmental bodies with responsibilities in the } \\
\text { energy sector into one unit }\end{array}$} & + & + & + & + & + & + & + & + & + & + & + & + & + & + & + & + \\
\hline \multicolumn{2}{|c|}{$\begin{array}{l}\text { Deploy incentives for efficient energy production, transmission } \\
\text { and distribution }\end{array}$} & + & + & + & + & + & + & + & + & + & + & + & + & + & + & + & + \\
\hline Place a strong focus on foster & ing and stimulating niches & + & + & + & + & + & - & - & + & + & - & - & + & + & + & + & + \\
\hline
\end{tabular}

Legend:

$+\quad$ positive effect

- $\quad$ negative effect

$0 \quad$ no / negligible effect

\subsection{Transition Management}

Once finished with the robustness analysis (the exercise done can be expanded), the execution phase can be entered using the data from the analysis done thus far, in particular the multi-level perspective, the scenarios and the robustness analysis. The main points are: 
- Create a normative scenario for communication purposes and to have a focus for all stakeholders;

- Create a so-called "transition arena" with stakeholders (including actors that belong to the niche level);

- Test important and far-reaching decisions on a strategic, tactical and operational level in each scenario and determine which ones bear the least risk going forward;

- Stimulate the emergence and diffusion of nicheinnovations;

- Enhance selection pressure on the regime through economic instruments (e.g., carbon taxes) and regulation (e.g., environmental legislation) (Geels 2012);

- $\quad$ Reiterate the scenario building exercise every 5 years (van der Heijden 2005);

- Use leading indicators to track towards which scenario the present is unfolding, such as, but not limited to:

○ Patterns of climate parameters (e.g. precipitation data, wind velocities);

○ Rate of deforestation;

- Number of IPPs willing to adjust existing PPAs;

$\circ \quad$ The amount of public resistance when implementing unpopular measures at an incremental level;

- Investment patterns in the Dominican Republic;

- Shifts in global tourism demand;

- The frequency and severity of natural disasters;

- Oil price behavior and forecasting thereof;

- Time between the deployment of new energy technologies in developed countries and the Dominican Republic;

- Energy consumption parameters, such as energy intensity;

- The frequency of sudden (global) events which impact the domestic energy sector.

\section{Conclusions and Recommendations}

In the analysis of the energy sector in the Dominican Republic it is evident that energy security exists at a low level. Furthermore, energy security appears to be under a greater threat regardless towards which scenario the present is unfolding. The used combination of concepts and approaches, while it has some drawbacks as discussed, has yielded some interesting results, like the identification of not only actors but also ideas, concepts, etc. that belong to either the regime or niche level, the critical internal and external uncertainties and the validity of different decisions in different scenarios (like for instance investing in only a few energy technologies, which is currently the case). thus, it has clearly identified the various roadblocks and windfalls that exist in the energy sector, and which steps need to be taken to deal with these aspects in the wake of both internal and external uncertainty.

Since developing countries are seldom the subject of such analyses, they are paradoxically more in need of them.
It is therefore advocated that similar exercises are done for other developing countries since these cope with specific characteristics not found in the developed world, and thus also not in research focusing on that part of the world. The latter implies that the findings of research on energy system transitions focusing in Western nations can't simply be adopted for developing nations. This paper has highlighted some aspects (important for energy system transitions) when studying regimes, niches and scenarios which are regularly associated with developing countries: poor policy making, vulnerable to climate change, small niche base, weak institutions, etc.

Energy system transition is a difficult task that spans decades. It is therefore advisable to identify the power relations in the energy sector and how to deal with that in the face of looming (internal and external) uncertainty. This combination of concepts and approaches has attempted to provide some insight in this matter for the Dominican Republic in order to help the energy system transition in this country forward in the desirable direction.

\section{References}

[1] Billiet, J., Loosveldt, G., Waterplas, L (1990), Het surveyinterview onderzocht, effecten van het ontwerp en gebruik van vragenlijsten op de kwaliteit van de antwoorden. S.O.I. reeks sociologische studies en documenten, Departement Sociologie, Sociologisch Onderzoeksinstituut, K.U. Leuven, Leuven

[2] Bryman, A. (2004), Social Research Methods. Second edition, Oxford University Press, New York

[3] Bulmer, M. Warwick, D. eds. (1993), Social research in Developing Countries, surveys and censuses in the third world, reprint 2004, UCL Press, London

[4] Burgos, F.J. (2008). Regional electricity cooperation and integration in the Americas: potential environmental, social and economic benefits. Organization of American States, Washington D.C.

[5] Contreras-Lisperguer, R., de Cuba, K. (2008), The potential impact of climate change on the energy sector in the Caribbean region. Organization of American States, Washington D.C.

[6] Conway, M. (2004), Scenario Planning: An Innovative Way to Strategy Development. Swinburg University of Technology

[7] Elliot, D., Schwartz, M., George, R., Haymes, S., Heimiller, D., Scott, G. (2001), Wind energy resource atlas for the Dominican Republic, U.S. Department of Energy, Oak Ridge

[8] Geels, F.W. (2002), "Technological transitions as evolutionary reconfiguration processes: a multi-level perspective and a case study", Research Policy 31, pp. $1257-1274$

[9] Geels, F.W. (2004), "From sectoral systems of innovation to socio-technical systems: Insights about dynamics and change from sociology and institutional theory", Research Policy 33, pp. 897-920 
[10] Geels, F.W. (2006), "Co-evolutionary and multi-level dynamics in transitions: The transformation of aviation systems and the shift from propeller to turbojet (1930 1970)", Technovation 26, pp. 999-1016

[11] Geels, F.W. (2007), "Analysing the breakthrough of rock ' $\mathrm{n}$ ' roll (1930-1970). Multi-regime interaction and reconfiguration in the multi-level perspective", Technological Forecasting \& Social Change 74, pp. 14111431

[12] Geels, F.W. (2010a), "Ontologies, socio-technical transitions (to sustainability), and the multi-level perspective", Research Policy 39, pp. 495-510

[13] Geel, F.W. (2010b), "A multilevel perspective on system innovation", Understanding Industrial Transformation. View from Different Disciplines. Olsthoorn X., Wieczorek A. (eds.), Springer, Dordrecht

[14] Geels, F.W. (2012), "A socio-technical analysis of lowcarbon transitions: Introducing the multi-level perspective into transport studies", Journal of Transport Geography, 24, pp. 471-482

[15] Granovetter, M. (1983), "The strength of weak ties: a network theory revisited", Sociological Theory 1, pp. 201233

[16] Grin, J., Rotmans, J., Schot, J. (2010), Transitions to Sustainable Development. New Directions in the Study of Long Term Transformative Change, Routhledge, New York

[17] Hanneman, R.A., Riddle M. (2005), Introduction to social network methods, University of California, Riverside, Riverside

[18] Hekkert, M., Suurs, R., Negro, S., Kuhlmann, S., Smits, R. (2007), "Functions of innovation systems: A new approach for analysing technological change", Technological Forecasting \& Social Change 74, pp. 413 - 432

[19] Izquierdo, L.R., Hanneman, R.A. (2006), Introduction to the formal analysis of social networks using mathematica, available http://luis.izqui.org/papers/Izquierdo Hanneman_2006version2.pdf (accessed December 18, 2011)

[20] Lachman, D.A. (2011), "Leapfrog to the future: Energy scenarios and strategies for Suriname to 2050", Energy Policy. 39, pp. 5035-5044,

[21] Lachman, D.A. (2013), "A survey and review of approaches to study transitions", Energy Policy 58, pp. 269-276

[22] Loorbach, D. (2010), "Transition Management for Sustainable Development: A Prescriptive, ComplexityBased Framework", Governance: An International Journal of Policy, Administration, and Institutions 23, pp. 161-183

[23] Loorbach, D., van den Brugge, R., Taanman, M. (2008), "Governance in the energy transition: Practice of transition management in the Netherlands", International Journal Environmental Technology and Management 9, pp. 294-315

[24] Loorbach, D., Rotmans, J. (2006), Managing transitions for sustainable development. Dutch Research Institute For Transitions, Rotterdam

[25] Magrin, G., Gay García, C., Cruz Choque, D. (2007), “2007: Latin America", Climate Change 2007: Impacts, Adaptation and Vulnerability. Contribution of Working Group II to the Fourth Assessment Report of the Intergovernmental Panel on Climate Change, Parry, M. L., Canziani, O. F., Palutikof, J. P., et al. (Eds.), Cambridge University Press, Cambridge, UK

[26] Meisen, P., Krumpel, S. (2009), Renewable energy potential of Latin America, Global Energy Network Institute, San Diego

[27] Minto, B. (1996), The Minto Pyramid Principle: Logic in Writing, Thinking, and Problem Solving. New and expanded ed., Minto Books International, Inc., London

[28] Nekkers, J. (2006), Wijzer in de Toekomst. Werken met toekomstscenario's, Uitgeverij Business Contact, Amsterdam

[29] Nexant (2010), Caribbean regional electricity generation, interconnection and fuels supply strategy, Nexant, White Plains

[30] OAS (2007), Sustainable energy policy initiative report for Latin America and the Caribbean, Organization of American States, Washington D.C.

[31] Ogilvy, J., Smith, E. (2004), "Mapping Public and Private Scenario Planning: Lessons from regional projects", Development. Vol.: 47, No.: 4, Society for International Development, s.l.

[32] Raven, R., Verbong, G. (2007), "Multi-Regime Interactions in the Dutch Energy Sector: the Case of Combined Heat and Power Technologies in the Netherlands 1970-2000", Technology Analysis \& Strategic Management 19, pp. 491507

[33] Rip, A., Kemp, R., (1998), "Technological change", Human Choice and Climate Change. Eds. Rayner, S., Malone, E., vol. 2. Battelle Press, Columbus, pp. 327-399.

[34] Scearce, D., Fulton, K., the Global Business Network (2004), What If? The Art of Scenario Thinking for Nonprofits, Global Business Network, Emeryville

[35] Schwartz, P., and Ogilvy, J.A. (1998), "Plotting your Scenarios", Learning from the Future. Competitive Foresight Scenarios. Eds.: Fahey, Liam and Randall, Robert M., John Wiley \& Sons, Inc., New York

[36] Shove, E. (2012), "Energy Transitions in Practice. The Case of Global Indoor Climate Change", Governing the Energy Transition. Reality, Illusion or Necessity? Eds. Verbong G. and Loorbach D. Routledge, New York

[37] Smith, A., Voß, J., Grin, J. (2010), "Innovation studies and sustainability transitions: The allure of the multi-level perspective and its challenges", Research Policy, 39 (4), pp. 435-448

[38] Sovacool, B.K. (2009), "Rejecting renewables: The sociotechnical impediments to renewable electricity in the United States", Energy Policy 11 (37), 4500 - 4513

[39] Star, J., Randall, D. (2007), "Growth Scenarios: Tools to Resolve Leaders' Denial and Paralysis", Strategy \& Leadership, Vol. 35, No. 2, p 56 - 59

[40] Strauss, A., Corbin, J. (1998), Basics of Qualitative Research, Sage Publications, Thousand Oaks 
[41] Taylor, J.B. (1999), The Robustness and Efficiency of Monetary Policy Rules as Guidelines for Interest Rate Setting by the European Central Bank, Stanford University, s.l.
[42] van der Heijden, K. (2005), Scenarios. The Art of Strategic Conversation, Second edition John Wiley \& Sons, Chichester. 